\title{
The Analysis of MOUs and their Activities Related to Port State Control
}

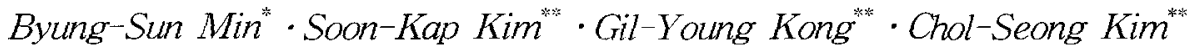 \\ Yoon-Sok Lee $e^{* * *} \cdot J u n g-M a n K_{i m}^{* * *} \cdot$ Chung-Ro Lee \\ *Korean Resister of Shipping, Daejeon, Korea \\ **Korea Maritime University, Pusan, Korea \\ ***:Korea Institute of Maritime and Fisheries Technology, Pusan, Korea
}

\begin{abstract}
The Memorandum of Understanding (MOU) is the document of intent signed between the Port States Control(PSC) to undertake a uniform manner as agreed. Though the MOU is not a legally binding, in case where the agreed items are violated without a just cause, the denunciation will follow. International Maritime Organization (IMO) and regional MOUs have been making amendments and reinforcing the relevant requirements, so that port State Authorities can effectively eradicate the substandard vessels. However, the various problems have arisen due to the existence of different requirements of each MOU, the lack of information exchange between each MOU, the lack of uniform PSC implementation within the same MOU and the lack of adequate system due to the short history of MOUS. In this paper, the MOU records for three years (1999 -2001) were analyzed according to each MOU, type of ship, deficiency code, classification society, the number of inspected ships and the number of detained ships to assess the problems (Statistics during 2002 will be published after August 2003). The purpose of this study is to help better understand the PSC activities within each MOU and to establish effective countermeasures by grasping the problems that exist in the PSC at present.
\end{abstract}

Key words : The Memorandum of Understanding (MOU), Port State Control, Statistics, classification society

\section{Introduction}

Port State control (PSC) is a system of harmonized inspection procedures designed to target substandard ships with the main objective being their eventual elimination. Port States are entitled to control foreign ships visiting their own ports to ensure that any deficiencies found are rectified before they are allowed to sail.

It is well known that the responsibility for ensuring that ships comply with the provisions of the relevant instruments rests upon the owners, masters, recognized organization and the flag State administrations. However, the primary responsibility to safeguard against substandard ships lies on with the flag States.

Regrettably, some flag States fail to fulfill their commitments contained in agreed international legal instruments and subsequently some ships are sailing in an unsafe condition, threatening the lives as well as the marine environment. It is when flag states fail to meet their commitments that port State comes into play.

For the effective understanding of PSC activities, maritime Authorities have joined the regional Memorandum of Understanding (MOU) as a member. The Paris MOU is the model upon which other regions of the world base their agreements on PSC. Starting with the Paris MOU, PSC became more organized and widespread and now there are various Memorandum of Understanding on port States control covering almost every part of the world. At present, there are eight regional agreements on PSC with the total of 123 members states.

In recent years, the importance of PSC has been widely recognized by the shipping industry and there has been important movement in various regions toward establishing a harmonized method for the effective implementation of the control provisions. The followings are the Memorandum of Understanding on PSC in the world up to this date.

- Paris MOU (Europe and North Atlantic region)

- Acuerdo de Viña del Mar (Latin American region)

- Tokyo MOU (Asia-Pacific region)

- Caribbean MOU (Caribbean region)

- Mediterranean MOU (Mediterranean region)

- Indian Ocean MOU (Indian Ocean region)

- Abuja MOU (West and Central African region)

- Black Sea MOU (Black Sea region)

After the casualty of M/T ERIKA-25years old, 35,000dwt tanker broken in two parts and eventually sank off the coast of Brittany on December 12, 1999, the main criticism of PSC broke out due to that the established safety net of inspections by the flag State, port State, industry and classification society failed to keep their safety nets.

* Corresponding Author : Byung-Sun Min, bsmin@krs.co.kr

** \{soonkap, gykong, cskimu, lys, jmkim\} @bada.hhu.ac.kr

**** crlee(@) post.webkimft.or.kr 
Following the $\mathrm{M} / \mathrm{T}$ ERIKA incident, there has been gradual trend among port Authorities to implement more rigorous PSC inspections to prevent environmental pollution and to maintain the safety of vessels. And as one of these tough measures, MOUs have recently developed new regimes such as strict target matrix, target system and European Quality of Shipping Information System (EQUASIS) in order to identify and eliminate sub-standard vessels.

Although MOU is understood as having an important role to prevent a marine pollution, the MOU is not an international convention and has no official status within the International Maritime Organization (IMO). However, the agreement on port State control has certainly had an impact on international rule making in the IMO. Also, since the conventions usually require lengthy ratification procedures and similar problems when there is a need for conventions to be amended, a MOU has been established instead of a convention.

\section{Statistical analysis data of each MOU}

The MOU records for three years (1999 -2001) were analyzed to assess the problems. More detailed data per member States, Flag States, Ship Type, Classification Societies, and Deficiency Categories are displayed in each MOU Annual Reports.

\subsection{Number of ships inspected}

Paris MOU : The total number of inspections are increasing slowly through the year of 1999 -2001 from 18,399 to 18,681 and also, the number of detained ships are increased upon reaction of increased inspections. Approximately $30 \%$ of the ship was inspected two(2) times within the year.

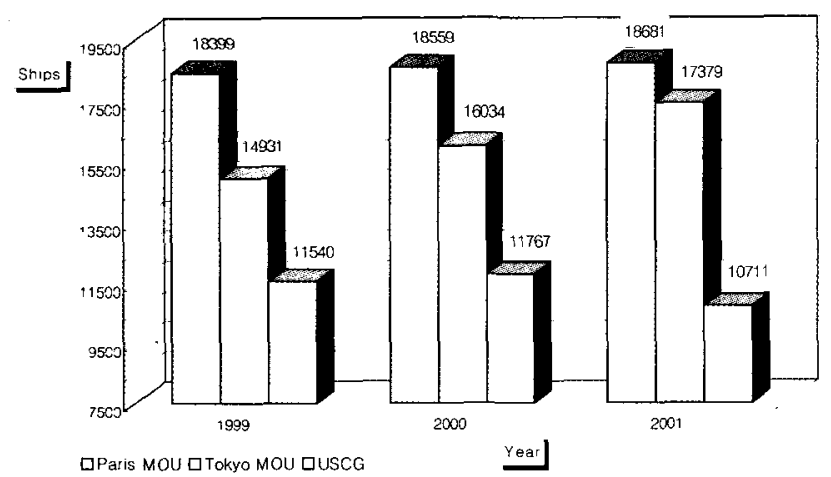

Fig. 1 Number of ships inspected per each MOU

Tokyo MOU : The total number of inspections are increasing slowly through the year of 1999 2001 from
14,931 to 17,379 and also, the number of detained siips are increased upon reaction of increased inspections.

USCG : The total number of inspections is stable. But, the number of detained ship is reduced through the year of $1999 \sim 2001$.

The number of ship inspected in major MCUs are increasing slowly. In other words, it is regarded a settled state.

\subsection{Detention ratio per vear}

Paris MOU : From the $1995(11.21 \%)$ to $1998(9.06 \%)$, the detention ratio was decreasing through the Paris, MOU. However, in recent years, it is stable slowly as per Table 1 due to the rigorous inspections by member Authori ies.

Tokyo MOU : From the 1994(3.80\%) to 1998(7.2c\%), the detention ratio was increasing gradually. After 1998, it is stable as per Table 1 due to the endeavoring to reduce PSC detention by the Owner or organization concerned.

USCG : From the $1997(7.12 \%)$, the detention ratio was decreasing steeply as per Fig. 2 due to the endeavoring to reduce PSC detention by the Owner and recognized Organizations. The main reason of steep decreasing is the strong disadvantage to the ship classed target system such as port entry restriction until the ship is confirmed no deficiency.

Until now, in Paris MOU and Tokyo MOU, they do not use a past detention data as a tool for a direct disadvantage to the ship owner, Flag States or Classification Society. However, they will apply a strong restriction to the all parties, as USCG, especially a sub-standard vessel within the years.

Table 1 Average detention ratio per each MOU

\begin{tabular}{|c|c|c|c|}
\hline Detention ratio & $1999(\%)$ & $2000(\%)$ & $2001(\%)$ \\
\hline \hline Paris MOU & 9.15 & 9.50 & 9.09 \\
\hline Tokyo MOU & 7.18 & 6.87 & 7.76 \\
\hline USCG & 3.37 & 2.52 & 2.21 \\
\hline
\end{tabular}

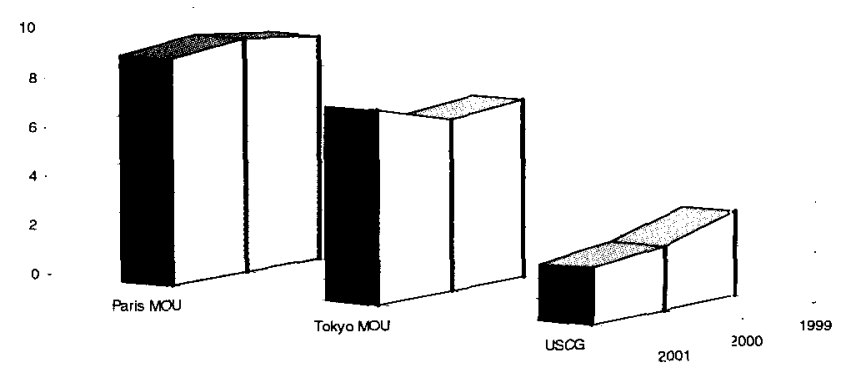

Fig. 2 Trend of detention ratio per each MOU 


\subsection{Inspection efforts of members per each MOU}

Paris MOU : The final goal of inspection ratio to each member Authorities is 25\%. In 2001, the Paris MOUs average inspection ratio for individual foreign merchant ships which entered in their ports was $27.3 \%$. Most of the member States achieved an annual total of inspections rate to $25 \%$. According to the average detention ratio during 1999 2001, Russia(44.8\%) and Croatia(44.5\%) are especially higher than other members of Ireland(14.4\%), France $(12.0 \%)$.

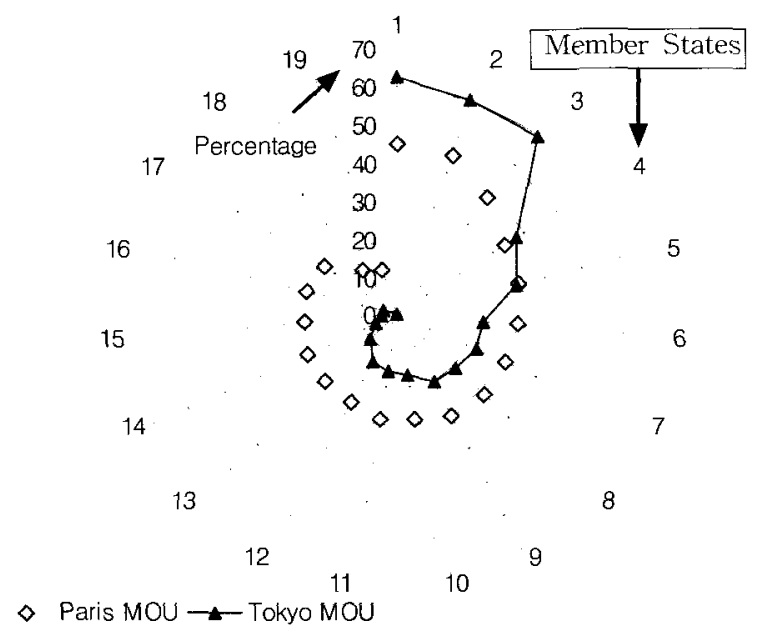

Fig. 3 Average percentage of inspection ship calls per members in 1999 2001

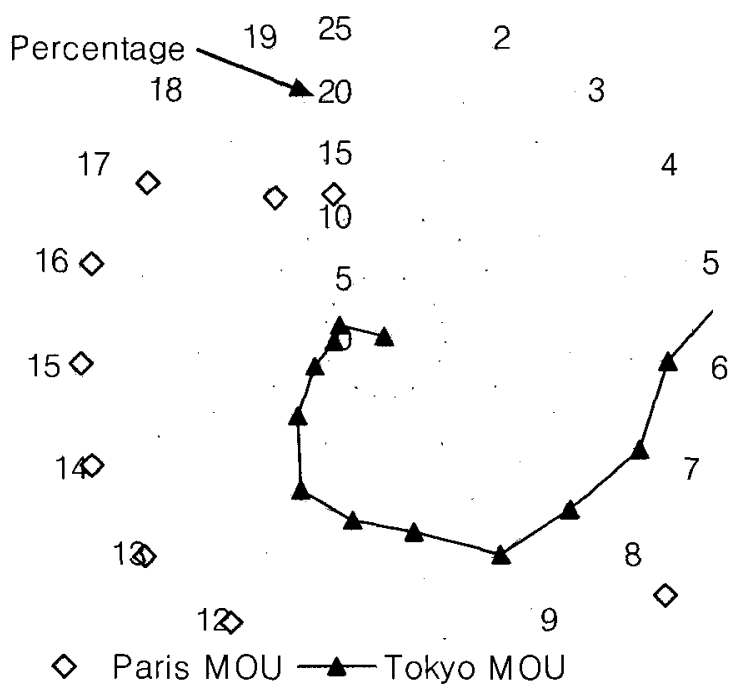

Fig. 3-1 Details within the area of $25 \%$

Tokyo MOU : The regional annual target inspection rate is $75 \%$. According to the Annual Report on PSC in the Asia-Pacific Region 2001, the average inspection rate the average inspection rate through Tokyo MOU is $71 \%$ in
2001. The Japan(4,498 ships inspected in 2001), Australia (2,913 ships) and Republic of $\operatorname{Korea}(2,340$ ships) are the major countries in view of number of ships inspected in their ports. However, the Fiji(29 ships inspected in 2001), Vanuatu(0 ships) and Papua New Guinea(0 ships) are the countries having only a few inspections.

Judging by the above fact, the inspection percentage has a wide gap between member Authorities.

\subsection{Detention ratio per Member Authorities}

Paris MOU : The average detention ratio through the MOU is $9.09 \%$ in 2001 . The detention ratio for three years of the Greece (15.2\%), Portugal (14.0\%) marked especially higher compare to other States, the Sweden (2.0\%), France $(5.3 \%)$. The higher difference of detention ratio between member States is $13.2 \%$.
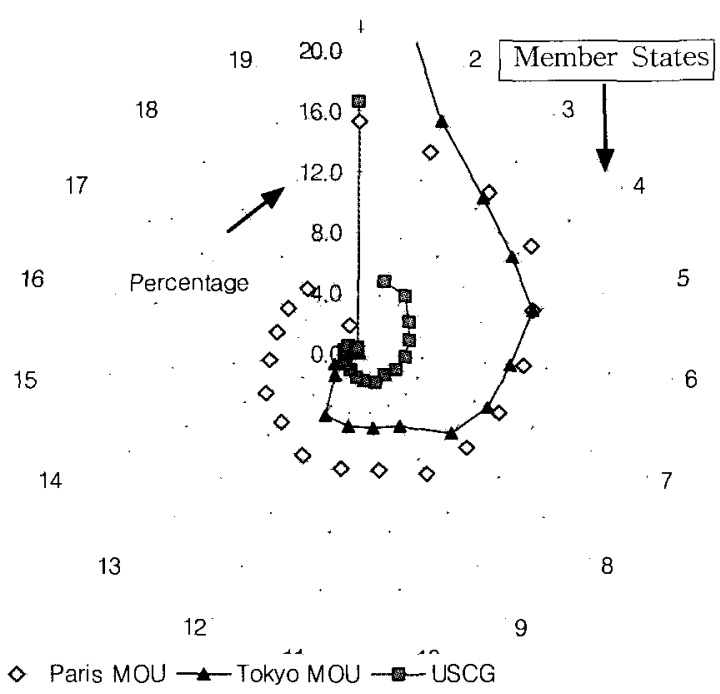

Fig. 4 Average detention ratio per members resulted of their activities in $1988 \sim 2000$

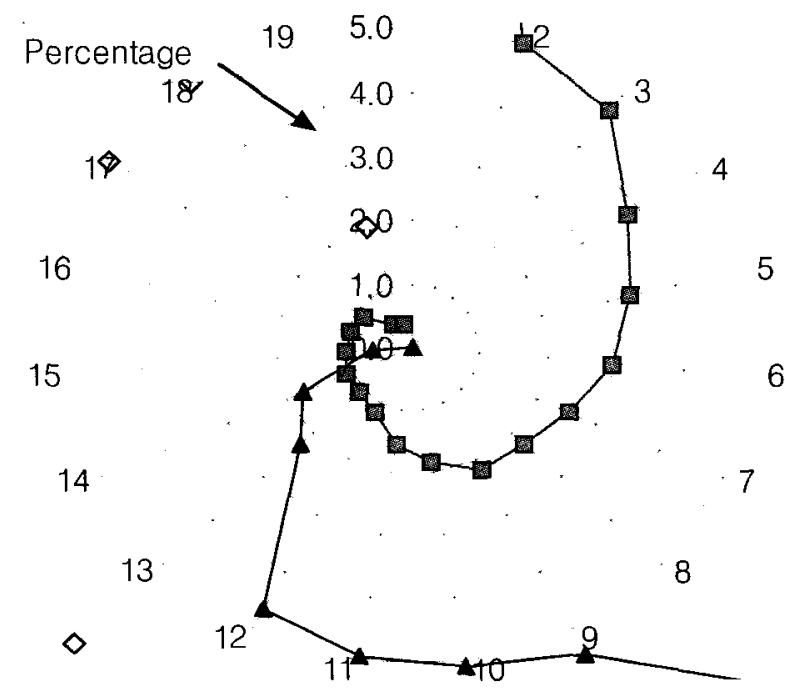

Fig. 4-1 Details within the area of $5 \%$ 
Tokyo MOU : The average detention ratio through the Tokyo MOU is $7.76 \%$ in 2001 . The detention ratio of each year is not steadied yet. For example, the Thailand $30.1 \%$ in $1999,43.6 \%$ in $2000,23.7 \%$ in 2001 ), has a gap compared with each year. The detention percentage between member Authorities also has a wide the Thailand scored a $32.47 \%$ and gap. For example,the Indonesia scored $0.32 \%$ of detention rate.

USCG : It is noteworthy that outside of the main continent, such as Guam(2.6\%), Hawaii(2.9\%) and Alaska(Anchorage : 3.8\%) were recorded high detention ratio. Miami(5.0\%), Providence(Rhode island : 3.5\%) is especially higher than other states of Savannah $(0.4 \%)$, San Francisco $(0.87 \%)$.

The detention ratio between member States has a wide gap.

\subsection{Detention ratio per target flag list in 2001}

Paris MOU : The performance of each flag State is produced Black, Gray and White List. The left side graph is including only the flag State classed with the Black list in 2000. The Bolivia, Albania, Sao Tome \& Principe, Honduras, Lebanon, Syrian Arab Republic, Cambodia, Belize, Algeria, Libyan Arab Jama., Turkey, Romania and Georgia classed to a Very high risk in the Black List.

Tokyo MOU : This graph is including only the flag State classed with Target flag. The Korea, Dem. Peoples Republic (40.4\%) and Indonesia (28.7\%) are especially higher than other flag States.

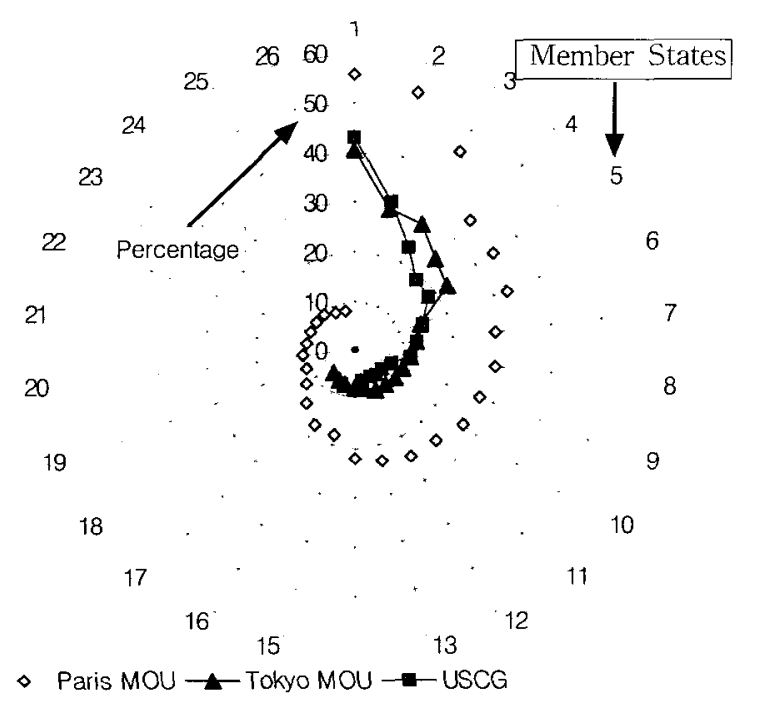

Fig. 5 Average detention ratio in 1999 2001 per target flag

USCG : The Target flag Administrations were identified as having a detention ratio higher than the 3 -year overall average and were associated with more than one detention in 2000. The 3-year(1999 - 2001) overall average was $2.7 \%$. Bolivia(42.86\%), Belize(23.1\%), and Cambodia(30.8\%) are especially higher than other flag States. From 2002, Target flag States is identified as having detention ratio higher than the overall average and were associated with more than one detention in the previous three years

The detention ratio between Flag States classed with Target Flag has a wide gap due to lack of their duty.

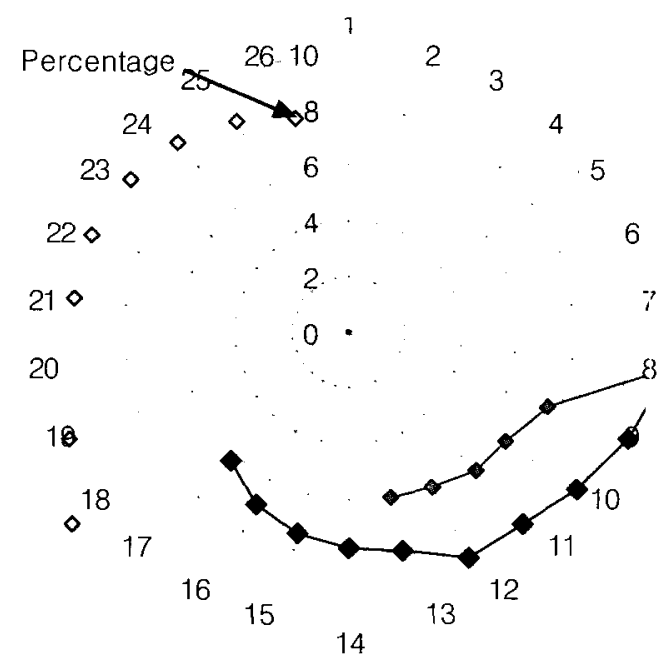

Fig. 5-1. Details within the area of $10 \%$

\subsection{Detention ratio per ship type}

Paris MOU : The major types of ship inspected are General dry cargo (79,313 among 18,681) and Bulk carriers (3,150 among 18,681). The major types of ship detained are also General dry cargo (1,096 among 1,699) and Bulk carriers (273 among 1,699). The Concentrated Inspection Campaign(CIC) highlights on Oil tanker from 1 Se tember to 30 November 2000 due to that the accident of Tanker/Comb. Carrier may provoke the biggest problem in marine environmental. Therefore, the detention ratio of Oil tanker was decreased due to strict inspections.

Tokyo MOU : In 2001, 1,349 detentions were warranted to ships registered in 59 countries due to serious deficiencies found on board. It is noted that $13.1 \%$ of the General dry cargo ship inspected were detained especially higher than other types.

Gas Carrier is less detained than others in spice of a rigorous inspections.

Table 2 Average detention ratio in 1999 - 2001 per ship type

\begin{tabular}{|c|c|c|c|c|c|}
\hline Ship Type & $\begin{array}{c}\text { Paris } \\
\text { MOU(\%) }\end{array}$ & $\begin{array}{c}\text { Tokyo } \\
\text { MOL(\%) }\end{array}$ & Ship Type & $\begin{array}{c}\text { Paris } \\
\text { MOL(\%) }\end{array}$ & $\begin{array}{c}\text { Tokyo } \\
\text { MOL(\%) }\end{array}$ \\
\hline General Drv Cargo & 12.7 & 13.1 & Other Types & 6.0 & 3.6 \\
\hline Bulk Carrier & 8.9 & 4.4 & Ro-Ro/Container $/$ ehicle & 4.2 & 3.9 \\
\hline Refrigerated Carrier & 7.7 & 7.9 & Passenger ship/Ferry & 5.8 & 4.5 \\
\hline Chemical Tanker & 7.0 & $\mathbf{4 . 6}$ & Gas Canier & 2.0 & 2.9 \\
\hline Tanker/Comb. Carrier & 6.0 & $\overline{5.5}$ & &
\end{tabular}


Byung-Sun Min · Soon-Kap Kim · Gil-Young Kong $\cdot$ Chol Seong Kim · Yoon-Sok Lee · Jung-Man Kim · Chung-Ro Lee

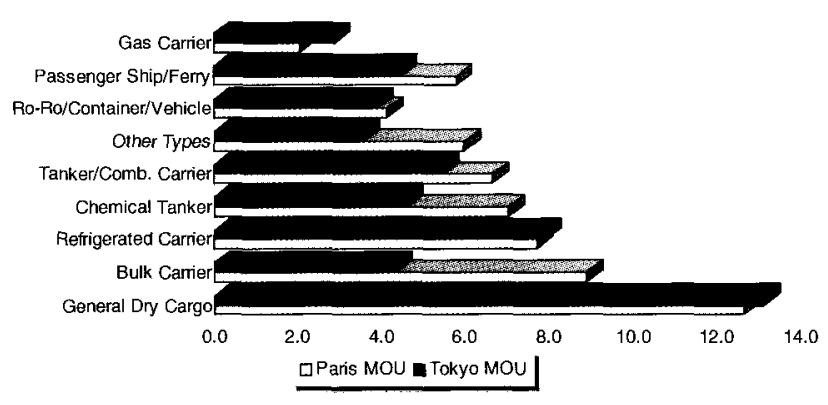

Fig. 6 Comparison of detention ratio per ship type

\subsection{Detention ratio per classification Societies (IACS member only)}

Paris MOU : Number of ships classed with European classifications is larger amount than others. The average detention ratio of ships with class-related detainable deficiency in 2001 is $2.0 \%$. The detention ratio of CCS, RS and $\mathrm{KR}$ is higher than the average detention ratio.

Tokyo MOU : The average detention ratio in Tokyo MOL is $7.76 \%$. The regime of class-related deficiencies is in force but the data of statistics are not published yet.

USCG : The average detention ratio of ships with class related detainable deficiency in 2001 is $0.40 \%$. Class-related detentions of 3-year rolling average are reducing steeply (1999-0.79\%, 2000-0.48\%, 2001-0.40\%). $\mathrm{RS}, \mathrm{KR}$ and CCS still remained the Target class and also, have a small amount of ship entered in U.S.A. From 2002, the new method holds all classification society to the same performance standards.

Table 3 Average detention ratio with class-related deficiencies in 1999 2001

\begin{tabular}{|c|c|c|c|}
\hline Classifications & Tokyo MOU(\%) & Paris MOU(\%) & USCG(\%) \\
\hline RINA/CCS & $6.55 / 5.91$ & $3.05 / 2.47$ & $0.21 / 0.51$ \\
\hline $\mathrm{RS} / \mathrm{KR}$ & $12.29 / 6.16$ & $2.02 / 3.13$ & $2.90 / 1.43$ \\
\hline $\mathrm{NK} / \mathrm{BV}$ & $4.21 / 7.24$ & $1.89 / 1.70$ & $0.28 / 0.16$ \\
\hline $\mathrm{LR} / \mathrm{ABS}$ & $4.21 / 4.57$ & $1.63 / 1.50$ & $0.28 / 0.18$ \\
\hline $\mathrm{DNV} / \mathrm{GL}$ & $3.67 / 5.03$ & $1.07 / 0.73$ & $0.05 / 0.14$ \\
\hline
\end{tabular}

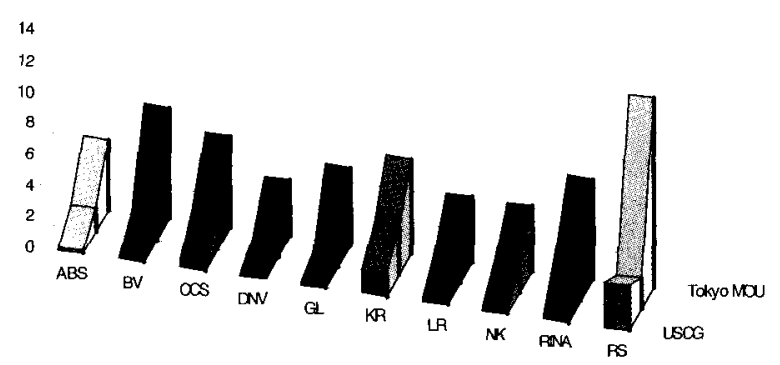

Fig. 7 Comparison of detention ration per Class
Tokyo MOU has not published the detention ratio as per class related matter therefore, the detention ratio is especially higher than other MOU. Recent year, a small size Societies, such as KR, CCS, are improving their PSC results by means of various counter measures.

\subsection{Number of deficiencies per major categories}

Paris MOU : The major categories of deficiencies are the Life saving appliances, Safety in general, Fire safety measures and Safety of navigation.

Tokyo MOU : The major categories of deficiencies are the Life saving appliances, Fire safety measures, Safety of navigation and Safety in general. The major deficiency categories are same as Paris MOU.

The Life saving appliances and Fire safety measures are the secondary barrier in order not to progress next stage of casualty. In other words, it is only used when an emergency situation occurred. Therefore, it is easy to careless to maintain well.

Table 4 Average detention ratio in 1999 - 2001 per deficiency items

\begin{tabular}{|c|c|c|c|c|c|c|c|}
\hline \multicolumn{2}{|r|}{ Detention Ratio } & $\begin{array}{c}\text { Paris } \\
\text { MOU }(\%\end{array}$ & $\begin{array}{l}\text { Tokyo } \\
\text { MOU (\%) }\end{array}$ & \multicolumn{2}{|r|}{ Detention Ratio } & $\begin{array}{c}\text { Paris } \\
\text { MOU }(\%)\end{array}$ & $\begin{array}{l}\text { Tokyo } \\
\text { MOU (\%) }\end{array}$ \\
\hline 1 & Life saving appliances & 17.3 & 20.0 & 14 & Food and catering & 1.7 & 0.7 \\
\hline 2 & Satety in general & 13.3 & 10.9 & 15 & ISM & 1.0 & 1.1 \\
\hline 3 & Fire Safety measures & 13,2 & 14.7 & 16 & Mooring arrange. & 1.1 & 1.1 \\
\hline 4 & Safety of navigation & 11.3 & 12.1 & 17 & Carri. Carg/dang good & 1.3 & 0.9 \\
\hline 5 & MARPOL - annexI & 7.1 & 6.5 & 18 & MARPOL - annexV & 0.8 & 0.1 \\
\hline 6 & Load lines & 5.5 & 7.6 & 19 & Work spaces(IL0147) & 0.9 & 0.5 \\
\hline 7 & Propulsion laux machin & 5.2 & 3.3 & 20 & MARPOL -operat defi. & 0.9 & 1.5 \\
\hline 8 & Ship's cert. Idocuments & 5.5 & 4.2 & 21 & Alarm -signals & 0.5 & 0.3 \\
\hline 9 & Radio communication & 3.9 & 4.7 & 22 & Oil, Chemi ./Gas carrier & 0.3 & 0.2 \\
\hline 10 & Crew and Accomo. & 3.1 & 1.3 & 23 & Other deficiencies & 0.2 & 0.7 \\
\hline 11 & Accident provention & 2.1 & 0.9 & 24 & MARPOL - annex II & 0.1 & 0.1 \\
\hline 12 & Cert/watch. for crew s & 2.0 & 1.6 & 25 & MARPOL - annex III & 0.1 & 0.0 \\
\hline 13 & SOLAS - operat . defi ci & 1.6 & 4.2 & & & & \\
\hline
\end{tabular}

Detention percentage per items

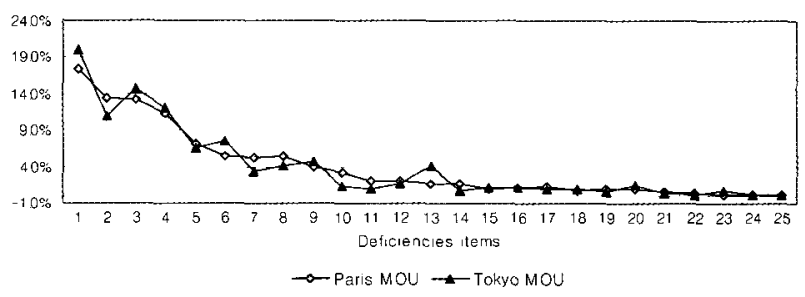

Fig. 8 Comparison of deficiency ratio per categories

\subsection{ISM related deficiency numbers per each MOU}

Until now, the major categories of deficiency are the Fire safety measures, Life saving appliances, Safety in general, not an ISM matter. However, deficiencies related ISM Code are steeply increasing through the years at all MOUs. 
Passenger ships regardless of tonnage and oil tankers, chemical tankers, gas carriers, bulk carriers, cargo high-speed craft of 500 gross tons and more were applied the ISM Code from July 1 1998. Other cargo ships 500 gross tons and more are to comply with the ISM Code from July 12002 .

To reinforce the message of strong policing, the Paris MOL, in conjunction with the Tokyo MOU, will conduct a three months campaign of expanded inspection of vessels subject to the provisions of the ISM Code. This campaign was run from July 12002.

Considering that the ISM Code undoubtedly contributed to the overall improvement in ships quality, ISM related deficiencies might be a major category of PSC deficiencies within the few years later.

Table 5 Number of ISM related deficiency

\begin{tabular}{|c|c|c|c|}
\hline ISM related deficiencies & 1999 & 2000 & 2001 \\
\hline \hline Paris MOU & 494 & 929 & 1239 \\
\hline Tokyo MOU & 531 & 719 & 792 \\
\hline USCG & 34 & 60 & 128 \\
\hline
\end{tabular}

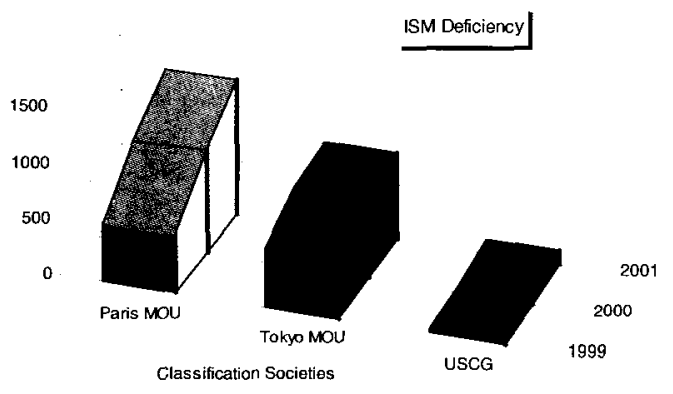

Fig. 9 Trend of ISM related deficiency

\section{Conclusion}

According to the above mentioned research which analyzed the requirements of each MOUs and gathered statistics of PSC activities for the last three years, there are some problems as follows which need to be resolved by ship owners, ship masters, port authorities, flag state administrations or regional MOUs to effectively attain the final goal:

Firstly, there are two main deficiency categories - life saving appliance and fire fighting measures. These serve as the secondary barriers to stop the progression of next stage of casualty. In other words, they are only used when a real emergency occurs. Under the normal operational circumstances, they are not likely to be used. Therefore, it would be easy to be careless about maintaining them in good working order. The other main deficiency category is the in general. This category serves as the primary barrier in comparison with the life saving appliance and fire fighting measures when it comes to maintaining the safety of ship. The deficiency in this category may result in the major casualty.

Secondly, the activities of PSC are not uniformly applied even in the same MOU region. Following the increase in the number of MOUs, the numbers of port authoriies have also increased over the years without confirming their capacity to undertake PSC suitably. This situation has led to the different standards being applied by the different inspectors. More simply stated, even if the internationally uniform standards are established, the disparity may still result because the interpretation of such standards depends on the competence of each inspector.

Thirdly, the decision to detain a vessel is based on the professional judgment of individual PSC officer. This means that the unduly detention of ship may occur due to the lack of trained personnel. Also, once the vessel is detained by the ill decision of PSC officer, the appeal to reverse the detention is often not successful because the PSC officer usually stands firm by his/her decision.

Finally, there is a problem of frequent on board inspection performed by the different port authorities within a short span of time even though there was no deficiency found during the previous inspection. This is due to the fact that there is lack of inspection history exchange between the MOUs.

To undertake PSC activities in more effective manner, I suggest as following points;

Firstly, the PSC inspections should concentrate more on the category of safety in general as it is a more essential matter when it comes to preventing a major marine casualty.

Secondly, it is necessary to cooperate closely with the MOUs to share the obtained information in order to identify the substandard ships. From this point of view, IMO and MOU have tried to develop new schemes such as a brand new computerized database system or the EQUASIS.

Thirdly, It is imperative to develop close co-operation between flag States and port States having recognized that the main responsibility for compliance with the provisions of the relevant instruments lies with the flag State.

Finally, The professional qualifications of PSC officers should be also at the same level by the means of profound training program or seminars in lights of the fact the decision to detain a vessel is based on the judgment of the PSC officer. 
In addition, ISM Code which is to ensure safe practices in ship operation and to improve ship management and thereby reduced human error, should be a main instruments for implementation of PSC.

In case of USCG, the detention ratio has been decreasing gradually through the years. The rigorous regimes, such as restriction of entry to US port or cargo operation until the vessel is inspected for the target classed vessel, are of a help to reduce the substandard vessels.

It is noteworthy that the essential responsibility for compliance with the provisions of the relevant instruments lies with shipowner and operator. The primary responsibility for demonstrating such compliance remains with the flag State or recognized organizations which are authorized to perform the control on behalf of flag States. The second responsibility for confirming such compliance lies with the port Authorities and classification Society.

As a final word, it should be noted that in the past, the reputation to the flag State, owner and recognized organization were judged by outcome of marine casualty such as an oil spill; a sinking or a loss of lives. However in recent years, the potential defects are increasingly used as a factor to decide of the reputation of Flag State, owner and ROs. That is to say, the deficiencies pointed out by PSCO are regarded as a first step in the chain of events that would eventually lead to a marine casualty. Not surprisingly, PSC will play a greater role in the eradication of substandard vessels as a close partner of flag state.

\section{References}

[1] Acuerdo de Viña del Mar : Internet Home Page http://200.45.69.62"

[2] DR Z. OYA ÖZçAYIR : PORT STATE CONTROL -Maritime Law Consultant Member of IMO Roster of Experts and Consultants. P113 184, P209-233.

[3] Mediterranean MOU : Internet Home Page http://www.medmou.org"

[4] Paris MOU : (1999) ANNUAL REPORT

[5] Paris MOU : (2000) ANNUAL REPORT
[6] Paris MOU : (2001) ANNUAL REPORT

[7] Paris MOU : PARIS MEMORANDUM OF UNDERSTANDING ON PORT STATE CONTROL

[8] Paris MOU : Internet Home Page http://Www.parismou.org"

[9] Tokyo MOU : ANNUAL REPORT ON PORT STATE CONTROL IN THE ASIA-PACIFIC REGION (1999)

[10] Tokyo MOU : ANNUAL REPORT ON PORT STATE CONTROL IN THE ASIA-PACIFIC REGION (2000)

[11] Tokyo MOU : ANNUAL REPORT ON PORT STATE CONTROL IN THE ASIA-PACIFIC REGION (2001)

[12] Tokyo MOU: MEMORANDUM OF UNDERSTANDING ON PORT STATE CONTROL IN THE ASIAPACIFIC REGION

[13] Tokyo MOU : THE PORT STATE CONTROL MANUAL

[14] Tokyo MOU : Internet Home Page http://www.tokyo-mou.org"

[15] United States Coast Guard : (1999) PORT STATE CONTROL REPORT

[16] United States Coast Guard : (2000) PORT STATE CONTROL REPORT

[17] United States Coast Guard : (2001) PORT STATE CONTROL REPORT

[18] United States Coast Guard : FOREIGN FRIGH'T VESSEL EXAMINATION BOOK CG-840 FV Rev. $1 / 01$

[19] United States Coast Guard : FOREIGN TANKER VESSEL EXAMINATION BOOK CG-840 TVE Rev. $1 / 01$

[20] United States Coast Guard : FOREIGN CHEMICAL, GAS, \& NATURAL GAS TANK VESSEL EXAMINATION BOOK CG-840 LOC Rev. 1/01

[21] United States Coast Guard : USCG Marine Safety Manual, Vol.II: Materiel Inspection Section D : Port State Control

[22] United States Coast Guard : Internet Home Page http://www.uscg.mil/hq/g-m/psc/psc.htm"

Received 29 May 2003

Accepted 29 July 2003 